\title{
Constitucionalidad y procedimiento democrático
}

Rodolfo Vázquez

F. 112 de junio del presente año se publicó en el Diario Oficial la Ley de Participación Ciudadana del Distrito Federal. Dicha Ley, aprobada por la mayoría del PRI y sin el concurso del resto de los partidos en la - Asamblea Legislativa del Distrito Federal, excluye a los partidos políticos de la elección de los consejos ciudadanos.

Tal eliminación de la mediación partidista viola lo dispuesto en el artículo 41 constitucional que a la letra dice:

Los partidos políticos son entidades de interés público; la ley determinará las formas específicas de su intervención en el proceso electoral.

Los partidos políticos tienen como fin promover la participación del pueblo en la vida democrática, contribuir a la integración de la representación nacional y como organizaciones de ciudadanos, hacer posible el acceso de éstos al ejercicio del poder público [...]

Contraviene, asimismo, el artículo 122 constitucional que se refiere al gobierno del Distrito Federal, y que en su fracción primera, inciso $e$ dice: "[...] La Ley [de Participación Ciudadana] establecerá la participación de los partidos políticos con registro nacional en el proceso de integración de los consejos ciudadanos".

Ante esta violación constitucional, el 3 de julio los partidos de oposición ejercieron una demanda por vía de acción de inconstitucionalidad en contra de la citada Ley. Esta acción, sin duda novedosa en elámbito jurídico mexicano, se fundamentó en los términos del artículo 105 constitucional, cuya reforma fue publicada en el Diario Oficial el 31 de diciembre de 1994 para entrar en vigor en enero de 1995.

El 10 de julio, el ministro instructor designado por la Suprema Corte resolvió desechar la demanda, por notoria improcedencia, al considerar que para la 
declaración de invalidez de las disposiciones impugnadas deberían examinarse normas generales de naturaleza electoral que, por tradición constitucional e institucional, son un impedimento para la Corte. ${ }^{1}$ En efecto, de acuerdo con el mismo artículo 105:

La Suprema Corte de Justicia de la Nación conocerá, en los términos que señale la ley reglamentaria, de los asuntos siguientes:

[...]

II. De las acciones de inconstitucionalidad que tengan por objeto plantear la posible contradicción entre una norma de carácter general y esta Constitución, con excepción de las que se refieran a la materia electoral $[\ldots]$

Desechada la demanda referida, el 14 de julio se interpuso un recurso de reclamación por el representante de los partidos de oposición en el cual se argumentaba que la violación cometida por la ley en cuestión alude a la exclusión de participar a los partidos políticos en la postulación de candidatos para la elección de consejeros ciudadanos, que constituye un derecho previo y anterior a lo que es propiamente el proceso electoral.

La reclamación recibió el apoyo del procurador general de la República:

[...] dicho recurso de reclamación, decía el procurador, debe ser admitido por esa Suprema Corte de Justicia, ya que es condición indispensable que se precise el alcance que la expresión "materia electoral" tiene en relación con el uso que de ella hace el primer párrafo de la fracción 11 del artículo 105 constitucional.

El procurador trata de demostrar que la expresión referida no es unívoca, clara ni precisa y, por lo tanto:

[...] no se puede rechazar por notoriamente improcedente una demanda con base en algo que no se sabe con precisión cuándo se aplica y cuándo no, especialmente porque al respecto ese alto tribunal no ha fijado un criterio preciso y constante durante los 78 años de vigencia de nuestra Constitución. ${ }^{2}$

${ }^{1}$ Proceso, núm. 982. México, 28 de agosto, 1995, p. 24.

${ }^{2}$ Antonio Lozano Gracia, "Comentario al recurso de acción de inconstitucionalidad en contra de la Ley de Participación Ciudadana del Distrito Federal”, en Procuraduría General de la República, Oficio núm. PGR 0383/95, 15 de agosto, 1995. 
No hace mucho el mismo procurador reiteró que la Suprema Corte de Justicia debe definir exactamente en qué puntos del ámbito político no puede tomar decisiones: "porque me parece que no todo lo que tiene que ver con elecciones es materia electoral, sino que también se relaciona con los derechos políticos fundamentales de los hombres". ${ }^{3}$

El 5 de septiembre, los once ministros de la Suprema Corte resolvieron por unanimidad que era procedente y fundado el recurso de reclamación interpuesto en contra del acuerdo inicial que desechó la demanda por vía de acción de inconstitucionalidad. Por lo tanto, la Corte daba entrada al recurso por considerar que el concepto materia electoral era un concepto "difícil" y, de esta manera, ganaba tiempo para fallar sobre su competencia o bien sobre la constitucionalidad o no de la referida ley. Por supuesto esta decisión fue saludada con beneplácito por los partidos de oposición y por el procurador general de la República, no así por el Ejecutivo Federal.

El presidente, el secretario de Gobernación y el regente capitalino se pronunciaron, inmediatamente, por la constitucionalidad de la Ley de Participación Ciudadana. Más aún, el regente enfatizó que por tratarse de un asunto electoral, la Corte está impedida para intervenir y que más bien de lo que se trata es que en las elecciones de noviembre participen exclusivamente quienes deben tomar parte, es decir, los ciudadanos; ${ }^{4}$ entiéndase, la sociedad civil.

Dados estos antecedentes las opciones posibles para la Corte, de acuerdo con el constitucionalista José Ramón Cossío, fueron las siguientes: a) pronunciarse en el sentido de que, en efecto, se trataba de materia electoral y, por lo tanto, declarar la demanda improcedente y sobreseída; b) pronunciarse en favor de la inconstitucionalidad de la ley pero sin alcanzar la mayoría calificada (ocho ministros de once) y, por lo tanto, sin que la sentencia tuviera efectos; c) pronunciarse por la inconstitucionalidad alcanzando la votación calificada y con efectos anulatorios generales; d) pronunciarse por la constitucionalidad de la ley que sólo exige la mayoría simple. Cualquiera de las posibilidades tendría efectos políticos trascendentes en vísperas de las próximas elecciones del 12 de noviembre. La decisión, la conocemos bien, fue la primera. El 31 de octubre la Suprema Corte dictaminó por seis votos a favor y cinco en contra, que era improcedente la demanda de inconstitucionalidad. El voto definitivo lo dio su presidente al momento de un empate técnico.

Traigo a cuento esta situación que se vive actualmente en México no, por supuesto, con el afán de mostrar la pugna política entre el partido mayoritario y los partidos de oposición, que salta a la vista por su obviedad y que forma

\footnotetext{
3 "La capital", en La Jornada. México, 20 de octubre, 1995.

4 "La capital", en La Jornada. México, 7 de octubre, 1995.
} 
parte del juego político en cualquier estado democrático; ni tampoco para mostrar lo que Alonso Lujambio ha calificado de "incongruencia política" del Poder Ejecutivo quien en su Plan Nacional de Desarrollo afirma que: "Los partidos políticos son el vínculo político por excelencia entre los electores y su gobierno" para defender ahora, con igual vehemencia, la constitucionalidad de la Ley de Participación Ciudadana que, como hemos visto, excluye la mediación partidista. ${ }^{5}$ A estas alturas a nadie sorprende este tipo de incongruencias.

Creo, más bien, que la importancia del asunto es especialmente relevante porque, como ha señalado Juan Molinar, dicho asunto: a) tiene que ver con una decisión que afecta gravemente los derechos políticos de los casi diez millones de habitantes del Distrito Federal; b) porque la exclusión de los partidos políticos de un proceso electoral en el que pueden participar más de cuatro millones de habitantes, estorba al desarrollo y fortalecimiento de los mismos; c) porque aceptar la idea de que la Corte no puede revisar la constitucionalidad de la Ley de Participación Ciudadana puede abrir la puerta a la impunidad gubernamental; y d) porque si la Corte se abstiene de intervenir en la materia dejaría fuera del marco de revisión jurisdiccional a la Ley de Participación Ciudadana, ya que ninguna otra autoridad de índole jurisdiccional estará capacitada para intervenir y, de esta manera, los ciudadanos y los partidos se quedarían sin autoridad alguna ante quien acudir para defender sus derechos. Se trataría, entonces, de un fuero total conferido a las instituciones amparadas bajo esa Ley. ${ }^{6}$

A la luz de estos hechos y comentarios recientes pienso, entonces, que resulta de interés volver a reflexionar sobre el problema que, a mi juicio, se halla en el fondo del asunto y que tiene que ver con la misma facultad que tienen los jueces para controlar la constitucionalidad de las normas jurídicas y sobre su posible activismo político. Con este propósito dividiré mi presentación en dos partes: I. ¿Cuáles son los argumentos en favor y en contra del control judicial de constitucionalidad?; y II. ¿Qué razones justificarían un papel activo de los jueces en el contexto de un Estado liberal democrático?

Parece que una de las características centrales de las democracias liberales consiste en la facultad que tienen los jueces para controlar la constitucionalidad

${ }^{5}$ Alonso Lujambio, "A ver Suprema Corte", en Reforma, sección editorial. México, 7 de julio, 1995.

' Juan Molinar, "Embrollo constitucional", en Reforma, sección editorial. México, 24 de julio, 1995. 
de las normas jurídicas -leyes o decretos, por ejemplo- que dictan los órganos democráticos -congreso o ejecutivo. Sin embargo, a pesar de su relevancia, la justificación de tal facultad de los jueces no es del todo clara. A su favor, se han aducido al menos dos argumentos: el de la supremacía constitucional y el del reconocimiento de derechos que, como espero mostrar, resultan lógicamente inconsistentes. En su contra, se ha argumentado con la conocida "dificultad contramayoritaria". Veamos, brevemente, cada uno de estos argumentos.

El primer argumento en favor del control judicial de constitucionalidad es el que hace derivar lógicamente dicho control de la supremacía de la Constitución.

El argumento parte de la idea de que en el caso de un conflicto entre la Constitución y una ley, el juez o debe aplicar la Constitución dejando de lado la ley, o aplicar la ley a expensas de la Constitución. Dado que la Constitución se reconoce como ley suprema, es decir, no sólo es una ley sino que define qué otras normas son leyes y el legislador no puede derogarla como otra ley ordinaria, sólo cabe la primera posibilidad, es decir, aplicar la Constitución dejando de lado la ley. Esta es la línea de argumentación de filósofos del derecho como Hart y Kelsen. Para el primero, la Constitución - si se identifica con la regla de reconocimiento- será el último fundamento para determinar la validez y pertenencia de las normas a un ordenamiento jurídico. ${ }^{7}$ Para el segundo, aunque la validez y pertenencia de la Constitución descanse en una norma supuesta -la norma fundamental- lo cierto es que en la pirámide jerárquica es la Constitución la que determina qué otras normas son válidas y pertenecen al ordenamiento jurídico. ${ }^{8}$ Si se reconoce la supremacía de la Constitución se sigue necesariamente el control judicial de constitucionalidad: los jueces no deben aplicar las normas contrarias a la Constitución. Cuando se niega ese poder a los jueces se está rechazando la supremacía de la Constitución; se la concibe, entonces, sin fuerza jurídica vinculante.

Contra este argumento, se ha señalado que no es verdad que siempre que una ley contradice las condiciones en cuanto a procedimiento y contenido que establece la Constitución, ella pierde fuerza obligatoria. Hay al menos tres circunstancias que pueden determinar que la norma siga siendo válida. Puede suceder: a) que la inconstitucionalidad no sea nunca planteada ante la justicia, por lo que aun cuando la ley sea objetivamente contradictoria con la Constitución mantendrá su fuerza obligatoria; b) que los tribunales se equivo-

${ }^{7}$ Véase Herbert L. A. Hart, El concepto de derecho. Trad. de Genaro Carrió. Buenos Aires, Abeledo-Perrot, 1990, cap. VI.

${ }^{8}$ Véase Hans Kelsen, Teoría pura del derecho. Trad. de Roberto Vernengo. México, unAm, 1979, v, 34. 
quen y declaren constitucional una ley que objetivamente no lo es, en cuyo caso la norma conservará su fuerza vinculante; y c) que los tribunales se nieguen a revisar la inconstitucionalidad por razones procesales, en cuyo caso también una norma objetivamente inconstitucional puede mantener su fuerza obligatoria. ${ }^{9}$

Kelsen advirtió tales dificultades y propuso que cuando una norma inferior es considerada válida, no obstante que contradice el texto explícito de una norma superior, ello implica que la norma superior tiene una "cláusula alternativa tácita" que permite el dictado de la norma inferior, aunque no se cumplan las exigencias de la parte expresa. La respuesta no es del todo convincente porque no tiene sentido la idea de la autorización que da una norma para que se dicten otras inferiores, si al lado de la autorización condicionada a que se satisfagan ciertas condiciones hay una autorización en blanco para que sean violadas esas mismas condiciones. ${ }^{10}$ Con todo, este intento de Kelsen deja ver, al menos, que el hecho de que una norma no pertenezca al sistema jurídico porque su dictado no estuvo autorizado por una norma superior que sí pertenece a ese sistema, no quiere decir necesariamente que aquella norma no sea válida o deje de tener fuerza obligatoria. Si aceptamos esta conclusión entonces no es cierto que un sistema que no cuente con un control judicial de constitucionalidad sea una imposibilidad lógica o excluya la supremacía de la Constitución. No hay ningún impedimento lógico para concebir cláusulas tácitas contingentes de la misma Constitución que establecieran que los mismos jueces y la Corte están obligados a aplicar una ley -contraria a lo establecido por la Constitución- si ella no es derogada por el órgano que la dictó o declarada inconstitucional por otro órgano político. Por lo tanto, la facultad de los jueces de declarar la inconstitucionalidad de las leyes puede estar ausente de ciertos sistemas jurídicos aun cuando cuenten con una Constitución suprema. El caso más claro, quizás, sea el de Gran Bretaña donde, como se sabe, su Constitución no es escrita pero goza de una enorme adhesión por parte del mismo Parlamento británico. Dígase lo mismo de los países escandinavos y de Holanda.

Un segundo argumento que se aduce en favor del control judicial de constitucionalidad tiene que ver con el reconocimiento de derechos.

Una de las funciones centrales de la Constitución, se afirma, es establecer derechos, y éstos son, por definición, límites o barreras a las decisiones de las mayorías en protección de intereses de los individuos. Si no hubiera control judicial no se reconocerían derechos ya que no habría límite alguno a las decisio-

9 Véase Carlos S. Nino, Fundamentos de derecho constitucional. Buenos Aires, Astrea, 1992, p. 675.

${ }^{10}$ Ibid., p. 676. 
nes de la mayoría expresadas a través de órganos políticos como el Congreso. La función de los jueces es, precisamente, proteger los derechos de los individuos. Por lo tanto, si se reconocen derechos, ello implica aceptar el control judicial de constitucionalidad.

Ante tal argumento cabe decir que si bien los derechos constituyen barreras de protección contra los intereses mayoritarios, de esto no se infiere que los derechos constituyan barreras contra las decisiones mayoritarias. No hay contradicción lógica en sostener que la única autoridad encargada de reconocer derechos es la del órgano mayoritario. Es concebible un sistema jurídico que reconociera derechos individuales, aunque su protección sólo quedara en manos de las mayorías a través del proceso democrático y no hubiera revisión judicial de las decisiones. ${ }^{11}$ Puede suceder que la mayoría esté tentada a suprimir los derechos de una minoría, pero no hay ninguna garantía de que otra minoría o individuos -los jueces- sirvan de mejor protección.

Si se acepta la crítica anterior al segundo argumento, ella misma nos lleva de la mano al planteamiento de la llamada "dificultad contramayoritaria" en contra del control judicial de constitucionalidad.

El constitucionalista estadounidense Alexander Bickel advirtió esta dificultad en los siguientes términos:

La dificultad radical es que el control judicial de constitucionalidad es una fuerza contramayoritaria en nuestro sistema [...] cuando la Suprema Corte declara inconstitucional una sanción legislativa o una acción de un Ejecutivo electo, ella tuerce la voluntad de los representantes del pueblo real de aquí y ahora [...] ella ejerce control no en nombre de la mayoría prevaleciente sino en su contra. Esto, sin connotaciones místicas, es lo que realmente sucede. El control judicial pertenece del todo a una pecera diferente de la democracia, y ésa es la razón de que se pueda hacer la acusación de que el control judicial es antidemocrático. ${ }^{12}$

Por su parte, el filósofo del derecho, Genaro Carrió, ha expresado la dificultad con las siguientes palabras:

Cómo es posible que una ley sancionada tras amplio debate por los representantes del pueblo democráticamente elegidos, quede sometida o supeditada, en cuanto a su validez constitucional, al criterio de los integrantes de un grupo aislado, no elegidos por procedimientos sufi-

11 Véase Carlos S. Nino, "Los fundamentos del control judicial de constitucionalidad", en Fundamentos y alcances del control judicial de constitucionalidad. Madrid, Centro de Estudios Constitucionales, 1991, p. 122.

${ }^{12}$ Alexander Bickel, The Least Dangerous Branch. The Supreme Court and the Bar of Politics. Citado por Carlos S. Nino, Fundamentos de derecho constitucional, p. 684 . 
cientemente democráticos, no controlados en su actuación por los representantes del pueblo y, en la práctica institucional efectiva, no responsables ante ellos. ${ }^{13}$

Si atendemos a los anteriores planteamientos no parece clara la fundamentación del control judicial en general pero, mucho menos, si tal control se realiza con respecto a las llamadas "cuestiones políticas". Si se ejerciera con respecto a estas cuestiones resultaría obvia la injerencia del Poder Judicial en los órganos democráticos. La posición más aséptica y, para muchos, la más jurídica, sugeriría, entonces, que la Corte, como dijo el ministro instructor en el caso de la constitucionalidad de la Ley de Participación Ciudadana, se declarara incompetente en tales materias.

Ahora bien, si partimos de la idea de que el juez sólo se limita a aplicar la ley o la Constitución sin valorarla, la falta de legitimidad democrática del juez parecería no ser relevante. Su actividad es la de un técnico o científico, y los científicos no son seleccionados por el voto mayoritario. Pero si se acepta que la tarea del juez es sustancialmente valorativa - ponderación de los principios básicos de moralidad social y en los distintos pasos de la interpretación jurídica-surge la pregunta siguiente: ¿Quién es un juez para sustituir al pueblo en general y a sus órganos más directamente representativos en tales valoraciones?

Es cierto que filósofos como Carrió, aun asumiendo el argumento contramayoritario, terminan defendiendo el control judicial. Carrió habla de una defensa condicionada del control judicial. Propone como condiciones, por ejemplo: idear un método más adecuado para la designación de los jueces en el que no sólo participe la Cámara de Senadores sino también la de Diputados; limitar la duración de los jueces en su cargo; introducir la institución de los amicus curiae con lo cual el debate judicial se volvería más democrático, etcétera. ${ }^{14}$ Algunas de estas condiciones se implementaron en México con las reformas recientes entre las que cabe destacar, además, la creación del Consejo de la Judicatura. Sin embargo, aún con todas estas modificaciones, la pregunta formulada más arriba sigue siendo válida: ¿Quién es un juez para sustituir al pueblo en general en decisiones sustancialmente valorativas? Es cierto que un proceso judicial implica alguna discusión pero de ninguna manera se trata de discusiones públicas e institucionalizadas en la que participan, con igual oportunidad, todos los que están afectados por la norma que se toma como base de la decisión.

Llegados a este punto tiene sentido preguntarse aún si el juez y especialmen-

13 Genaro Carrió, "Una defensa condicionada de la Judicial Review", en Fundamentos y alcances del control judicial de constitucionalidad, p. 148.

${ }^{14}$ Ibid., pp. 158 y ss. 
te la Corte Suprema deben jugar algún papel relevante en una sociedad democrática. Mi opinión es afirmativa y paso con ello al segundo apartado: ¿Qué razones justificarían un papel activo de los jueces en el contexto de un Estado liberal democrático aun aceptando la fuerza de la dificultad contramayoritaria?

\section{II}

No es mi propósito argumentar en estos momentos en favor de una democracia liberal. Sólo unas palabras para decir que, en la línea abierta por John Rawls -el Rawls de $A$ Theory of Justice-, me inclino por la aceptación de una justificación epistemológica de la democracia sobre la base de un objetivismo moral. Pienso que dicha justificación de la democracia provee las bases para la conciliación de ésta con un liberalismo igualitario en tanto que la democracia es el medio más apto para alcanzar el reconocimiento de los principios de autonomía, dignidad e igualdad de la persona - principios pilares de un liberalismo igualitario- con todos los derechos que de ellos se derivan; y no sólo los individuales sino también los sociales como una extensión natural de los primeros.

Con este marco de referencia, y siguiendo de cerca la propuesta del ya varias veces citado Carlos S. Nino, pienso que el primer argumento en favor de una participación activa de los jueces es la de ser custodios de la autonomía personal.

El argumento descansa sobre el mismo valor epistémico de la democracia. Este valor está dado principalmente por la tendencia inherente hacia la imparcialidad que tiene un procedimiento de discusión amplio y con posibilidades de participación igual. Si aceptamos, además, que existen dos tipos de principios morales posibles: los intersubjetivos (públicos y sociales), que valoran una conducta por sus efectos en los intereses de otros individuos; y los autorreferentes (privados y personales), que valoran una acción por los efectos en la propia vida de acuerdo con ideales de excelencia humana; entonces, el principio de imparcialidad y, por lo tanto, el valor epistémico de la democracia, no se aplica con respecto a las acciones autorreferentes dado que la validez de un ideal de excelencia humana no depende de que sea aceptable por todos en condiciones de imparcialidad.

Siendo así, los jueces no tienen razones para observar una norma jurídica de origen democrático que esté fundada en ideales personales. Por lo tanto los jueces deben revisar y si es el caso descalificar las leyes y otras normas democráticas de índole perfeccionista que pretendan imponer ideales de virtud personal. Esta es la protección judicial a la autonomía personal. ${ }^{15}$

El segundo argumento en favor de una participación activa de los jue- 
ces es el de constituirse en controladores del mismo procedimiento democrático.

Una concepción dialógica de la democracia en el marco de un liberalismo igualitario maximizará su capacidad epistémica si se cumplen algunas condiciones como, por ejemplo: la amplitud de participación de los afectados por las decisiones o medidas que se discuten; la libertad para expresarse en el debate y en la discusión; la igualdad de condiciones con que se participa; la exigencia de justificación de las propuestas; etcétera. Las reglas del proceso democrático deben asegurar que se den estas condiciones en el mayor grado posible.

Ahora bien, son precisamente los jueces quienes están obligados a determinar en cada caso si se han dado las condiciones que fundamentan el valor epistémico del proceso democrático, de modo que la ley en cuestión goce de una presunción de validez, que permita al juez poner entre paréntesis, a los efectos de justificar una decisión, su propia reflexión individual. Los jueces, como afirma John Ely, se convertirían entonces en una especie de referee del proceso democrático. Cumplirían con una función de "limpieza de canales" para hacer posible el cambio político y facilitar, entre otras cosas, la representación de las minorías. ${ }^{16}$

Si, finalmente, alguien preguntara por qué son mejores los jueces que los órganos democráticos para corregir y ampliar el proceso democrático, la respuesta sería que si el proceso democrático está viciado, él no puede tener la última palabra acerca de su corrección porque, como resulta obvio, carecería de valor epistémico. Que los jueces pueden equivocarse, no hay duda alguna. Pero el efecto de un control judicial de índole procedimental es el de promover las condiciones que otorgan valor epistémico al mismo proceso democrático. No sería función de los jueces imponer valores sustantivos que conduciría irremediablemente a un "perfeccionismo judicial", contrario a los principios de un liberalismo igualitario, como ya dijimos. Su función, reitero, sería la de preservar y promover el proceso mismo de participación democrática.

Si se acepta lo anterior, entonces estamos ya muy lejos de la pretendida asepsia que deben tener los jueces hacia la llamada "cuestión política". Todas las cuestiones que hacen al funcionamiento del proceso político -la libre expresión de las ideas; el funcionamiento de los partidos políticos; el proceso electoral; la división de poderes; la intervención federal, etcétera-deben ser objeto de aten-

15 Nótese que esta defensa incondicional de la autonomía personal supone una posición activa por parte de los jueces muy lejos de la pretendida pasividad que defienden los liberales a ultranza. En este sentido, es preferible referirse a la actividad de los jueces en términos de imparcialidad, que no excluye la toma de posición por razones de equidad, que en términos de neutralidad sí la excluye.

${ }^{16}$ John Ely, Democracy and Distrust. A Theory of Judicial Review. Véase Carlos S. Nino, Fundamentos de derecho constitucional, pp. 694-695. 
ción por parte de los jueces como parte del control judicial de constitucionalidad. Concluyo. En México el Poder Judicial no ha jugado históricamente un papel importante para preservar la desconcentración del poder, indispensable en una democracia liberal, y para evitar los desbordes de un Poder Ejecutivo centralizado en desmedro de los derechos fundamentales. A la luz de los argumentos presentados pienso que las reformas al artículo 105 constitucional fueron insuficientes y se debió eliminar la excepción sobre asuntos en materia electoral tanto por lo que hace a las controversias constitucionales como a las acciones de inconstitucionalidad. Esta hubiera sido la reforma de fondo.

No habiéndose hecho tal reforma -que sería deseable para un futuro- se abrió, sin embargo, una excelente oportunidad no sólo para poner a prueba la efectividad del recurso por acción de inconstitucionalidad con respecto a la Ley de Participación Ciudadana violatoria del 41 y 122 constitucional -como señalé al principio- sino también para convertir a los jueces en personajes activos para la consolidación de una auténtica democracia liberal. El sobreseimiento del recurso de reclamación confirma, una vez más, la timidez de una Corte que en aras de una no politización esconde, sin embargo, un preocupante sometimiento al Poder Ejecutivo y que en nada ayuda para asegurar su propia independencia. 